\title{
Spatial incongruence in the species richness and functional diversity of
}

\section{cricetid rodents}

Cintia Natalia Martín-Regalado, Miguel Briones-Salas, Mario C. Lavariega and Claudia E.

Moreno

S3 Table. Evaluation of spatial congruence between measures of biodiversity. The table includes percentages of communities per category of congruence, for species richness and functional diversity without the richness effect (SES.FD), at five resolutions. The colors match with the Figure 2 of the manuscript: green=high congruence, light orange=moderate congruence, and orange $=$ incongruence.

\begin{tabular}{|c|c|c|c|c|}
\hline Categories & $\begin{array}{l}\text { Low richness } \\
\text { (3-12 species) }\end{array}$ & $\begin{array}{l}\text { Moderate richness } \\
\text { (13-22 species) }\end{array}$ & $\begin{array}{l}\text { High richness } \\
\text { (23-32 species) }\end{array}$ & Total \\
\hline \multicolumn{5}{|l|}{ Resolution: 25 km $^{2}$} \\
\hline $\begin{array}{l}\text { SES.FD low } \\
(-3.77--1.52)\end{array}$ & 0.20 & 4.97 & 4.11 & 9.28 \\
\hline $\begin{array}{l}\text { SES.FD moderate } \\
(-1.51-0.73)\end{array}$ & 3.18 & 30.48 & 32.06 & 65.72 \\
\hline $\begin{array}{l}\text { SES.FD high } \\
(0.72-2.98)\end{array}$ & 2.09 & 15.73 & 7.18 & 25.00 \\
\hline Total & 5.47 & 51.18 & 43.35 & 100 \\
\hline \multicolumn{5}{|l|}{ Resolution: 50 km² } \\
\hline $\begin{array}{l}\text { SES.FD low } \\
(-3.61--1.65)\end{array}$ & 0.20 & 3.83 & 3.09 & 7.12 \\
\hline $\begin{array}{l}\text { SES.FD moderate } \\
(-1.64-0.30)\end{array}$ & 6.77 & 20.47 & 22.29 & 49.53 \\
\hline $\begin{array}{l}\text { SES.FD high } \\
(0.29-2.26)\end{array}$ & 12.08 & 16.69 & 14.58 & 43.35 \\
\hline Total & 19.05 & 40.99 & 39.96 & 100 \\
\hline \multicolumn{5}{|c|}{ Resolution: $100 \mathrm{~km}^{2}$ with the functional diversity (FD) index } \\
\hline $\begin{array}{l}\text { FD low } \\
(3.21-4.60)\end{array}$ & 22.95 & 0 & 0 & 22.95 \\
\hline $\begin{array}{l}\text { FD moderate } \\
(4.61-6.00)\end{array}$ & 4.07 & 26.99 & 0 & 31.06 \\
\hline $\begin{array}{l}\text { FD high } \\
(6.01-7.4)\end{array}$ & 0 & 12.02 & 33.97 & 45.99 \\
\hline Total & 27.02 & 39.01 & 33.97 & 100 \\
\hline
\end{tabular}




\begin{tabular}{|c|c|c|c|c|}
\hline Categories & $\begin{array}{l}\text { Low richness } \\
\text { (3-12 species) }\end{array}$ & $\begin{array}{l}\text { Moderate richness } \\
\text { (13-22 species) }\end{array}$ & $\begin{array}{l}\text { High richness } \\
\text { (23-32 species) }\end{array}$ & Total \\
\hline \multicolumn{5}{|c|}{ Resolution: $100 \mathrm{~km}^{2}$ with standardized effect size of functional diversity (SES.FD) } \\
\hline $\begin{array}{l}\text { SES.FD low } \\
(-3.06--1.31)\end{array}$ & 1.74 & 8.42 & 2.66 & 12.82 \\
\hline $\begin{array}{l}\text { SES.FD moderate } \\
(-1.30-0.42)\end{array}$ & 9.34 & 17.77 & 20.79 & 47.90 \\
\hline $\begin{array}{l}\text { SES.FD high } \\
(0.43-2.17)\end{array}$ & 15.66 & 13.00 & 10.62 & 39.28 \\
\hline Total & 26.74 & 39.19 & 34.07 & 100 \\
\hline \multicolumn{5}{|c|}{ Resolution: 200 km² } \\
\hline $\begin{array}{l}\text { SES.FD low } \\
(-2.74--1.15)\end{array}$ & 0.73 & 5.84 & 8.58 & 15.15 \\
\hline $\begin{array}{l}\text { SES.FD moderate } \\
(-1.14-0.45)\end{array}$ & 5.29 & 14.78 & 30.11 & 50.18 \\
\hline $\begin{array}{l}\text { SES.FD high } \\
(0.44-2.04)\end{array}$ & 7.66 & 14.23 & 12.78 & 34.67 \\
\hline Total & 13.68 & 34.85 & 51.47 & 100 \\
\hline \multicolumn{5}{|c|}{ Resolution: $400 \mathrm{~km}^{2}$} \\
\hline $\begin{array}{l}\text { SES.FD low } \\
(-2.79--1.79)\end{array}$ & 0 & 5.32 & 0.36 & 5.68 \\
\hline $\begin{array}{l}\text { SES.FD moderate } \\
(-1.78-0.26)\end{array}$ & 12.06 & 23.40 & 19.86 & 55.32 \\
\hline $\begin{array}{l}\text { SES.FD high } \\
(0.25-1.79)\end{array}$ & 14.18 & 15.25 & 9.57 & 39.00 \\
\hline Total & 26.24 & 43.97 & 29.79 & 100 \\
\hline
\end{tabular}

